\title{
RETRACTED ARTICLE: Progression of a serious game difficulty from a playful and pedagogical point of view: Analyze and representation
}

\author{
Adil Korchi ${ }^{1}$ (D) $\cdot$ Mohamed Dardor $^{2} \cdot$ Fayçal Messaoudi $^{3} \cdot$ El Houssine Mabrouk $^{4}$
}

Received: 10 February 2020 / Accepted: 18 June 2020/Published online: 14 December 2020

(C) Springer Science+Business Media, LLC, part of Springer Nature 2020

The Editor-in-Chief has retracted this article [1] because it significantly overlaps with a previously published conference paper by Carron et al. [2].

Adil Korchi disagrees with the retraction but has not explicitly stated whether he agrees to this retraction notice. The other authors did not respond to correspondence regarding this retraction.

\section{References}

1. Korchi, A., Dardor, M., Messaoudi, F. et al. Progression of a serious game difficulty from a playful and pedagogical point of view: Analyze and representation. Educ Inf Technol (2020). https://doi.org/10.1007 /s10639-020-10259-4

2. Thibault Carron, Mathieu Muratet, Bertrand Marne, Amel Yessad. Analyser et représenter la progression de la difficulté d'un jeu sérieux du point de vue ludique et pédagogique. EIAH 2017, Jun 2017, Strasbourg, France. https://hal.inria.fr/LIP6/hal-01515753v1

Supplementary Information The online version contains supplementary material available at https://oi. org/10.1007/s10639-020-10259-4.

Adil Korchi

adil.korchi@gmail.com

Mohamed Dardor

mohamed.dardor@usmba.ac.ma

Fayçal Messaoudi

faycal.messaoudi@usmba.ac.ma

El Houssine Mabrouk

abounadah@yahoo.fr

1 Faculty of Sciences and Technologies, University Sidi Mohamed Ben Abdellah, Fez, Morocco

2 Department of Informatics, faculty of Sciences, Dhar El Mehrez, Fez, Morocco

3 University Sidi Mohamed Ben Abdellah, National School of Business and Management, Fez, Morocco

4 Faculty of Sciences and Technics, Moulay Ismail University, Errachidia, Morocco 